\title{
Influence of standard of demand for automobiles on production figures of oil-producing organisations' subdivisions
}

\author{
Bauer Vladimir Ioganesovich \\ Dept. of Automobiles and Technological Machines Service \\ Tyumen Industrial University \\ Tyumen, Russia \\ vjbauer@mail.ru \\ Kozin Yevgeny Sergeevich \\ Dept. of Automobiles and Technological Machines Service \\ Tyumen Industrial University \\ Tyumen, Russia \\ eskozin@mail.ru
}

\author{
Mukhortov Aleksandr Alekseevich \\ Head of Social Development Department \\ Transneft Siberia, JSC \\ Tyumen, Russia
}

Bazanov Artyom Vladimirovich

Dept. of Automobiles and Technological Machines Service

Tyumen Industrial University

Tyumen, Russia

artyom777@mail.ru

\begin{abstract}
One of the ways of solving the problem of organising transport and technological service of oil-and-gas production processes is considered in the paper. The authors propose analysing the operation of the system of transport servicing of electric power generation management, when extracting oil and gas, as a queueing system. An algorithm of a simulation model of search for an optimal solution, concerning equipping the transport depots with machinery for servicing and repairing diesel-electric sets, was developed. The result of software realisation of the algorithm in the modeling environment "Anylogic 7.0" was shown. The developed model analyses the operation of diesel-electric sets and, in case of their failure or creation of demand for maintenance, sends service teams for rendering maintenance services. At that, such indicators of the system are registered as: the number of requests for machinery, mean wait of the request in a queue, etc. According to the results of the model operation, an optimizing model was built, which includes costs on machinery operation, as well as losses caused by idle time of generator sets. For the conditions of the model, an optimal number of machines, equal to two, were found. The standard of equipping the transport depot with lorries with sides for servicing generator sets was developed. The model of predicting the number of automobiles, using a key production figure of the workshop, was proposed. This model, in contrast to other strategies of managing transport-technological service, realised at the enterprises, allows predicting taking into account the changes of the key production figures of the workshop.
\end{abstract}

Key words - oil and gas extraction, vehicles, transport, queue system, demand for machinery

\section{INTRODUCTION}

Performance of labour-intensive works on construction, exploitation and maintenance of the objects of the oil-andgas producing sector is impossible without using vehicles and special machinery ( $\mathrm{V}$ and $\mathrm{SM}$ ). At that, costs on technical maintenance of $\mathrm{V}$ and $\mathrm{SM}$ during servicing the basic production reach $16-20 \%$ of the production cost of finished goods. An insufficient number of machinery units can be accompanied by idle time of the main production, but an excessive number of vehicles can also entail unjustified servicing costs [3]. Therefore, questions of determination of the optimal number of machinery for workshops and departments were and always remain of relevance.

The change of the organisational structure of oil-and-gas production departments (OGPD) also condition the necessity of actualization of earlier established standards of equipping enterprises with machinery. Nowadays, workshops accomplish only a part of the entire list of activities, earlier performed by OGPD; at that, they also engaged the machinery of service enterprises. One should note that existing approaches to creating a demand for machinery in other branches of economy are difficult to apply to the oil and gas sector $[7,10]$.

On the one hand, this solution allowed reducing costs on technical maintenance of $\mathrm{V}$ and SM; however, on the other hand, there should be an adjusted system of planning the demand for machinery at the enterprise so that it could correspond fully to production necessity. As a rule, the Transport Department of an oil-and-gas production organisation enters into an agreement with a contractor for the next year for a certain number of operation hours of every type of machinery for the workshop. The fund of machinery operation is planned by the principle "from the achieved", according to the settled results of the past years. Adjustments of already created plan are difficult; therefore, when forming it, it is necessary to take into account many production factors.

The workshops, similar at first sight in production figures (well stock, debit, amount of generated electric power), can differ considerably by a number of factors, for instance, by the volumes of introduction of new objects, by the technology of work performance, by dispersion of production capacities within the workshop, by availability of autonomous areas, etc. As of today, the majority of 
enterprises lack the methods allowing them to take into account the above-mentioned circumstances.

One of the departments using V and SM is Electric Power Generation Department (EPGD). The Department provides those oil-and-gas production enterprises with electric power where it is impossible to provide electric networks. In addition, it runs standby plants located at production facilities (for example, in oil treatment workshops). The Department structure includes gas turbine power plants, as well as mobile or stationary diesel-electric sets (DES), distributed over deposits. Each DES demands scheduled maintenance servicing (MS) (as a rule, every 250 hours of engine running) and doing current repairs (CR) with a certain periodicity. Lorries with sides, located in the central depot in the town, are engaged in performing these works.

In a general view, the system of transport servicing of the processes of electric power generation can be represented as a system of death and duplication [11]. The channel of servicing is machinery, called out on maintenance servicing of generator sets, which specify intensity $\lambda$ of requests. The intensity of requests is formed by the necessity of the planned maintenance servicing of the diesel-electric set, which is specified with a preset periodicity. Besides, it is necessary to do unplanned repairs. The main kinds of technical manipulations of the diesel power plant "ASDA-100" with engine YAMZ-238 are presented in table 1 .

TABLE I. LIST OF ACTIVITIES ON MAINTENANCE SERVICING OF DIESEL POWER PLANT

\begin{tabular}{|c|c|c|c|c|c|c|}
\hline & List of activities & $\begin{array}{l}\text { Chec } \\
\text { king } \\
\text { MS }\end{array}$ & $\begin{array}{l}\text { MS- } \\
250\end{array}$ & $\begin{array}{l}\text { MS- } \\
500\end{array}$ & $\begin{array}{c}\text { MS- } \\
100 \\
0\end{array}$ & $\begin{array}{c}\text { MS- } \\
200 \\
0\end{array}$ \\
\hline 1 & $\begin{array}{l}\text { External examination of } \\
\text { DES }\end{array}$ & 1 & 1 & 1 & 1 & 1 \\
\hline 2 & $\begin{array}{l}\text { Check of oil level in } \\
\text { crankcase, topping-up }\end{array}$ & 1 & & & & \\
\hline 3 & $\begin{array}{l}\text { Check of coolant level, } \\
\text { topping-up }\end{array}$ & 1 & 1 & 1 & 1 & \\
\hline 4 & $\begin{array}{l}\text { Check and servicing of } \\
\text { storage battery (SB) }\end{array}$ & 1 & 1 & 1 & 1 & 1 \\
\hline 5 & $\begin{array}{l}\text { Check of air filter } \\
\text { pollution, cleaning }\end{array}$ & 1 & 1 & 1 & & \\
\hline 6 & $\begin{array}{l}\text { Check of condition and } \\
\text { tightening of driving belt }\end{array}$ & 1 & 1 & 1 & 1 & 1 \\
\hline 7 & $\begin{array}{l}\text { Check of fixations and } \\
\text { conditions of hoses and } \\
\text { fitting pipes of cooling } \\
\text { system }\end{array}$ & 1 & 1 & 1 & 1 & 1 \\
\hline 8 & $\begin{array}{l}\text { Drain of water and dregs } \\
\text { from fuel sump }\end{array}$ & 1 & 1 & 1 & 1 & 1 \\
\hline 9 & $\begin{array}{l}\text { Check of force of } \\
\text { fasteners tightening }\end{array}$ & 1 & 1 & 1 & 1 & 1 \\
\hline
\end{tabular}

\begin{tabular}{|c|l|c|c|c|c|c|} 
& $\begin{array}{l}\text { Start of engine set, } \\
\text { warming it up to } \\
\text { operating temperature, } \\
\text { check of main parameters } \\
\text { of DES operation in no- } \\
\text { operation mode }\end{array}$ & 1 & 1 & 1 & 1 & 1 \\
\hline 1 & $\begin{array}{l}\text { Replacement of oil and } \\
\text { oil filter }\end{array}$ & & 1 & 1 & 1 & 1 \\
\hline 1 & $\begin{array}{l}\text { Replacement of fuel } \\
\text { filters }\end{array}$ & & & 1 & 1 & 1 \\
\hline 1 & Replacement of air filter & & & & 1 & 1 \\
\hline 3 & $\begin{array}{l}\text { Replacement of coolant } \\
\text { and filters of cooling } \\
\text { system }\end{array}$ & & & & & \\
\hline
\end{tabular}

The labour intensity of technical manipulations varies from 2 to 8 hours and is determined by the type of the performed work. The increase of the time of maintenance servicing can be caused by waiting for arrival of a spare part from stock and its delivery.

Intensity of servicing request $\mu$ is formed by the type of request, remoteness of the object from the machinery location and road conditions. The number of places in the queue is unlimited; however, after some time of waiting in the queue $\left(\tau_{\text {wait }}\right)$, the generator set can pass from the state "waits for MS, on" into the state "waits for repair, off". The system can be at several states:

$\mathrm{S}_{0}$ - all channels are free (DES does not require servicing and repair);

$\mathrm{S}_{\mathrm{k}}-\mathrm{k}$ channels are engaged, the rest are free;

$\mathrm{S}_{\mathrm{n}}$ - all $\mathrm{n}$ channels are engaged (entire machinery operates away from depot);

$\mathrm{S}_{\mathrm{n}+\mathrm{m}}$ - all $\mathrm{n}$ channels are engaged, $\mathrm{m}$ requests stand in epy queue.

The state graph of the system is given in Figure 1. From left to right, the state of the system transmits the flow of requests $\lambda$. From left to right, it relinquishes the channels; the flow of servicing $\mu$ is multiplied by the number of channels.

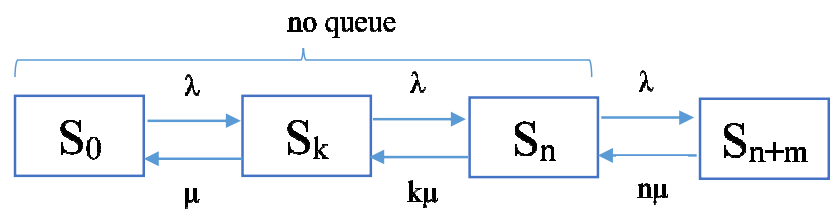

Fig. 1. State graph of transport servicing system of DES

The task of characterization of such system efficiency is a typical task of the queueing theory (QT). The mathematical apparatus of QT is widely used for solution of transport problems: beginning from the issues of increasing the functioning effectiveness of networks of urban streets [2], ending with applied studies in different branches [4, 6, $8,9]$. However, for applying the mathematical apparatus of 
QT, it is necessary to ascertain that random processes, flowing in the system, are Markov ones. Analysis of statistical information, obtained from profile enterprises, showed that this is not true.

The most convenient method for solution of this task will be the method of simulation modelling with a possibility of graphic visualisation of the model. Such possibility is presented by the simulation environment Anylogic. The structure of the transport servicing model of DES is similar to the example considered in $[1,5]$.

The enlarged flow diagram of the search for rational solution in the simulation model of servicing diesel-electric sets is presented in Figure 2.

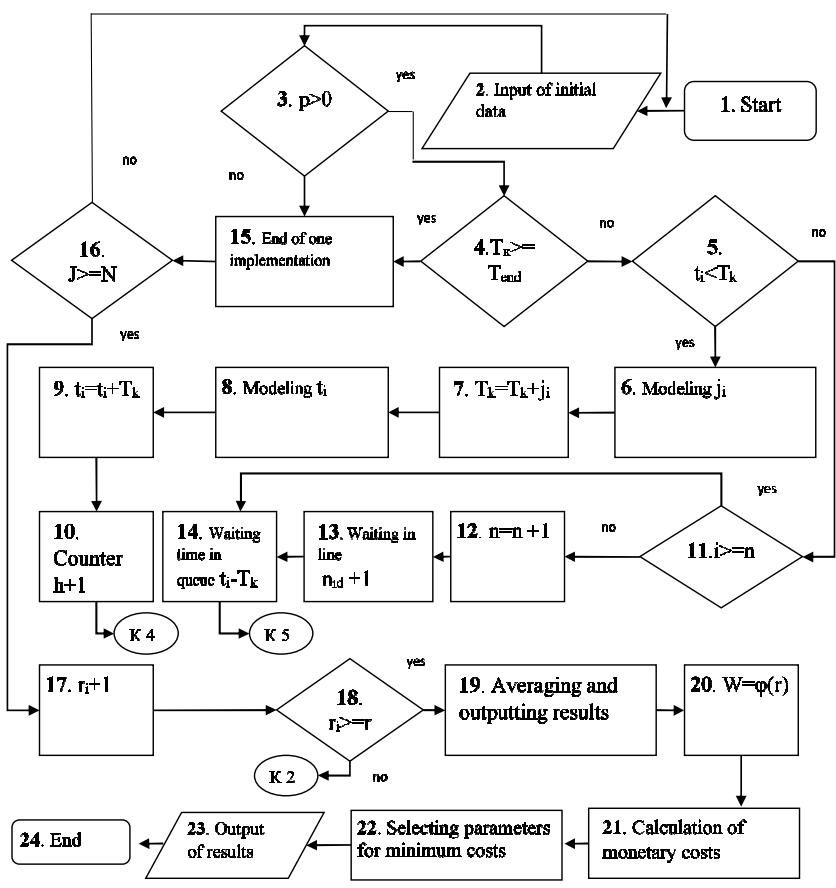

Fig. 2. Flow diagram of simulation model of transport servicing of power generation production

At the entrance to the model, a number of diesel-electric sets, a number of machinery units performing works on MS and the repairing of DES, remoteness of each DES from the place of machinery location, average schedule speeds of travelling to each DES are preset. The fault probability and nonfailure operating time of the machinery before MS are also specified (block 2). In block 2, the time of beginning and ending of the workday is recorded anew for every realisation. In this block, the diurnal operating time of DES is simulated. If the diurnal operating time exceeds the meantime-between-failures or MS, a request appears for the current day.

In block 4, the condition of finishing the simulation of one workday is checked. If the workday is not finished, the condition if the i-unit of machinery is free at the moment of $\mathrm{k}$-th request entrance is checked in block 5 . In block 6 , the time intervals among the recurrent requests for maintenance servicing or the repairing of DES are simulated. In block 7, the total time of arrival of the next request, calculated from the beginning of the workday, is determined. In block 8 , the time, spent on servicing one request, is simulated. At that, the servicing time depends on the remoteness of DES, on the access road condition. Also, in this block, the time of servicing is adjusted, proceeding from the type of request: MS or CR. Preliminary, as a result of processing the statistical dataб it was established that the time intervals between two subsequent requests are distributed by Erlang law:

$$
p(x)=\lambda \frac{(\lambda x)^{n-1}}{(n-1) !} e^{-\lambda x}
$$

and the servicing time of one DES is distributed by the normal law:

$$
p(x)=\frac{1}{\sigma_{x} \sqrt{2 \pi}} e^{-\frac{\left(x-m_{x}\right)^{2}}{2 \sigma_{x}^{2}}}
$$

In block 9, the time of vacating the i-th unit of machinery after repairing the k-th DES is determined. In block 10, the number of serviced generator sets is considered. In block 11, the condition whether all units of machinery are engaged is checked. In block 12 , the number of the machine, receiving DES for servicing, is determined. In block 13, the number of DES, waiting for servicing or repair, is recorded. In block 14 , the waiting time in the queue is calculated. In block 15, the result of the work of the transport depot per workday is fixed: the number of serviced requests - by the preset number of machines, the number of unserved requests because of busyness of the machinery, the number of requests waiting in queue, and the total waiting time in queue. In block 16, the condition whether the specified number of realisations is carried out is checked. In block 17 , the number of service brigades (machinery units) is changed.

In block 18 , the condition whether all the variants of the number of service brigades are considered is checked. In block 20, the theoretical regression line is constructed. In block 21 , cash expenditures are calculated and summed. In block 22, the rational number of machinery units is determined by the minimum of costs. The values of cash expenditures for different variants of parameters of equipment of the maintenance shed with machinery, obtained as a result of simulation, are reflected in the form of the graph (block 23).

The developed algorithm was realised by means of agent simulation in the environment "Anylogic". The deposit area, on which 41 diesel-electric sets operate, was taken as initial data. DESs are located in a random order at a distance from 0 to $200 \mathrm{~km}$ from the central maintenance shed. Such initial factors are typical for oil-and-gas-production organisations of Khanty-Mansi Autonomous Okrug. On the central maintenance shed, there are $\mathrm{N}$ machinery units, which are included in the mobile team for servicing and repairing DES. During simulation for the period of one year, the 
following parameters of the model functioning were recorded:

1. General number of requests, made in the system, equal to the ratio of the total number of MS (P) to the number of model realisations:

$$
\bar{n}=\frac{1}{\Psi} \sum_{y=1}^{\Psi} n
$$

2. Total volume of requests for $\mathrm{MS}$ and $\mathrm{P}$ falling to the transport depot, divided into requests, which will be serviced by the machines, available in the depot:

$$
\bar{n}_{s e r}=\frac{1}{\Psi} \sum_{y=1}^{\Psi} n_{s e r}
$$

and requests, waiting in queue owing to the shortage of machinery:

$$
M(\delta)=\sum_{\delta=0}^{\delta} k p_{\delta}
$$

3. At that, the mean wait in queue is determined:

$$
\bar{o}=\frac{1}{\Psi} \sum_{y=1}^{\Psi} o
$$

The window of the functioning simulation model is presented in Figure 3.

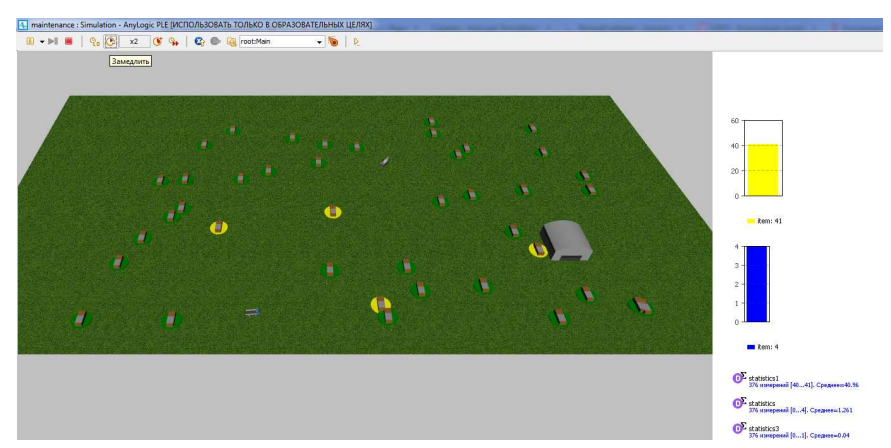

Fig. 3. Simulation model of system of transport servicing of diesel-electric sets in oil-and-gas extraction

In the active window of the model, the transport depot, diesel power plants in operation are shown, and the plants requiring maintenance servicing (4 units) are coloured in yellow in the field. On the right, the model statistics is represented: the number of operating plants, the number of engaged machinery units, the number of requests demanding repair.

Based on the analysis of the total costs by enumeration of different variants of machinery units, the variant that provides minimum of total costs $\Sigma \mathrm{C}$, which is made up of costs $\mathrm{C}_{\mathrm{tr}}$ on machinery maintenance and of costs $\mathrm{C}_{\mathrm{id}}$ resulted from idle time of diesel-electric sets with observance of the technology and periodicity of the scheduled works, is determined:

$$
\sum C=C_{t r}+C_{i d} \rightarrow \min
$$

It is necessary to note that a specific structure of expenditure forming exists at each oil-and-gas producing enterprise. Therefore, economic data on the costs per hour of machinery operation and losses, related to the failure of DES, have to be specified for each specific case. For the simulation model under consideration, the following expert data were used: the cost per hour of the idle time of DES is 150 thous. RUB; the cost per hour of machinery operation is 1000 RUB. The optimal condition for the model is the use of 2 machinery units for servicing and repairing DES. The results of simulation are presented in table 2 and figure 4 .

TABLE II. SIMULATION RESULTS OF THE SYSTEM OF TRANSPORT SERVICING.

\begin{tabular}{|c|c|c|c|c|c|c|}
\hline $\begin{array}{c}\text { Num. of } \\
\text { vehicles }\end{array}$ & $\begin{array}{c}\text { Numbe } \\
\text { r of } \\
\text { request } \\
\text { s } \\
\text { waiting } \\
\text { time for } \\
\text { maintena } \\
\text { nce, } \\
\text { hours }\end{array}$ & $\begin{array}{c}\text { Averag } \\
\text { e } \\
\text { service } \\
\text { time, } \\
\text { hours }\end{array}$ & $\begin{array}{c}\text { Cost of } \\
\text { machinery, } \\
\text { RUB. }\end{array}$ & $\begin{array}{c}\text { Cost of } \\
\text { generator's } \\
\text { idle time, } \\
\text { RUB. }\end{array}$ & $\begin{array}{c}\text { Total costs, } \\
\text { RUB. }\end{array}$ \\
\hline 1 & 505 & 60.3 & 4.5 & 2272500 & 9037500 & 11310000 \\
\hline 2 & 510 & 35.2 & 5.0 & 5100000 & 5280000 & 10380000 \\
\hline 12 & 506 & 3.5 & 4.8 & 29145600 & 531750 & 29677350 \\
\hline
\end{tabular}

Analysis of the simulation results allows concluding that with the increase of the number of machinery units, the idle time of DES, waiting for servicing, reduces. The number of requests for current repair also reduces. This entails the reduction of expenditures, related to the idle time of DES (money losses because of the use of spare DES, production downtime while waiting for repairing the set; expenditures related to purchasing electric power from third-party producers, etc.). However, the expenditures on machinery operation increase (capital charges, drivers' wages, POL (petroleum, oil, lubricants), etc.).

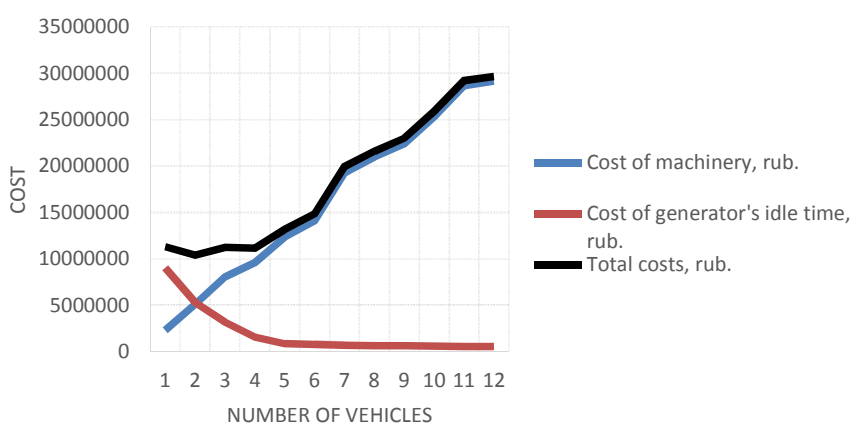

Fig. 4. Diagram of objective function change

By the results of the poll of the experts, working in the Department of electric power generation, a key production figure - the number of DES - determining the demand for 
machinery, was identified. It is obvious that the number of lorries with sides depends on the number of generator sets, serviced by them: the more generators will be in operation, the more vehicles are required for their servicing and repairing. There is some threshold number of DES. In case of exceeding this number, one vehicle will be insufficient. Taking into account the distribution of sets over deposits, the vehicle will be unable to service all the requests, as a result of which a queue will appear. To manage the production, it is necessary to determine the type of the dependence of changing the number of machinery units on the DES number.

For this, a specified number of realisations were performed with different quantity of diesel-electric sets, after which the optimal values of the quantity of lorries with sides in the transport depot were determined by criterion (7). The obtained dependence is described by the polynomial curve, presented in Fig. 5.

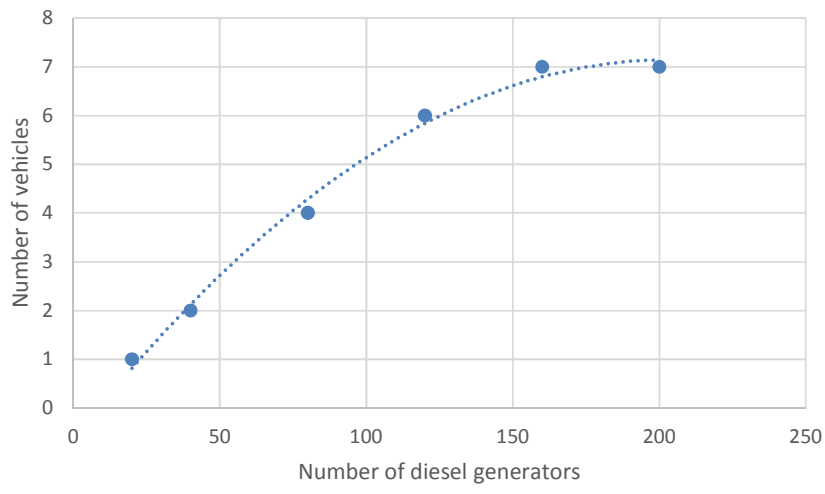

Fig. 5. Dependence of number of vehicle units for services on number of generator sets

Using the method of correlation and regression analysis, the model, describing the revealed dependence, was developed:

$$
\mathrm{Q}=-0.0002 \mathrm{~N}_{\text {gen }}^{2}+0.0766 \mathrm{~N}_{\text {gen }}-0.6395 \text {, }
$$

where Q - number of units of lorries with sides, required for servicing generator sets, unit;

$\mathrm{N}_{\text {gen }}$ - production figure for the workshop number of DES.

The index of multiple determination for the model equals 0.97 , which indicates its adequacy. The model is adequate for the studied range of values of the independent variable: $\mathrm{N}_{\mathrm{gen}}=20 \div 200$, which corresponds to the current state and predictions of the growth of workloads in the Generation Department.

However, for practical use, the standard in the form of the specific indicator, which can be used for calculations, is of great interest.
Therefore, the standard of the demand for lorries with sides to service and repair DES was developed. The general view of the design formula of determining the volume of transport services is given below:

$$
Q=H \cdot N_{g e n},
$$

where $\mathrm{H}$ - annual norm of demand for lorries with sides, multiplied by the production figure and equal to 59 machine-hours of vehicle operation per 1 diesel-electric set or 0.05 of the vehicle (with annual fund of vehicle's operating time equal to 4015 hours).

Owing to the fact that, when planning the machinery operation for the subsequent periods, the indicators of the machinery operation time in machine-hours are used, the corresponding standard was proposed. Each department or workshop is allotted a certain number of hours of vehicles' operation, which then are distributed by the operation mode depending on production conditions in the workshop, its remoteness from central depots, by the composition of the teams, etc. Let us suppose that per the same annual number of machine-hours, the workshop can use one twenty-fourhour vehicle or two one-shift vehicles. Therefore, for planning transport service of the processes of oil-and-gas production, it is convenient to use the standard in machinehours, which for specific conditions can be converted subsequently into the number of vehicles by formula (10):

$$
N_{t r}=\sum \frac{Q}{S h},
$$

where Sh - duration of the operation shift of the lorry with sides in the workshop, $h$.

In case of the fractional number of machinery units, the result should be approximated by the mathematic rules.

The presented model allows predicting the demand for technological transport when changing the key production figures of the workshop. It takes into account the production and technological factors of the oil-and-gas branch, as well as the technology of performing the works on technical maintenance of diesel-electric sets, by which it substantially differs from the existing studies in this field.

In general, one of the three strategies of managing technological transport can be present at the enterprise (Figure 6). 


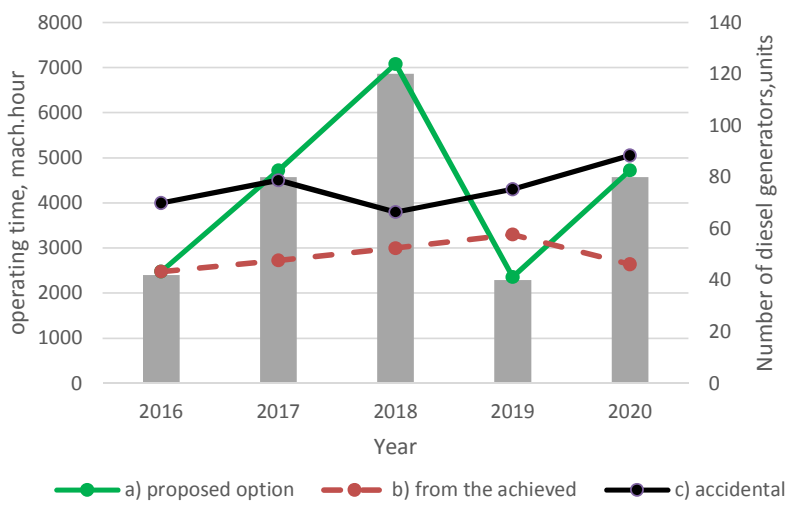

Fig. 6. Strategies of planning demand for machinery of oil-and-gas producing enterprises

The first strategy (Figure 6, b) was considered at the beginning of the paper; it is characterised by the formation of the number of vehicles for the predictive period by the results of the last years. At that, if the key production figure of the workshop grows, the management agrees on the growth of the number of transport, as a rule, by $5-15 \%$ higher than the indicator of the previous period. Although when the production figure changes, the volume of transport services changes as well. This strategy does not imply the established model of interrelation of two indicators. Therefore, the first strategy is inert (in the example, in Figure 6, when the indicator decreased in 2016, the load of transport work continues to grow, and in 2020, when more vehicles are required, the reverse situation takes place); the predictive number of vehicles does not correspond to the real demands of the production for them. This decreases considerably the accuracy of prediction.

The second strategy (figure 6, c) can be called a strategy of "random control". In this case, there are no mechanisms, interconnecting production factors and equipment of subdivisions with technological transport. Transport service is managed under the influence microeconomic, political factors, as well as on the grounds of short-term gain. At that, the presence of the excessive number of transport at the enterprise is also possible (Figure 6, 2016). Along with it, in other periods, there can be a considerable shortage of it (Figure 6, 2018).

The third strategy (Figure 6, a) of managing transport services is offered by the authors. In contrast to the previous ones, it implies an established functional or stochastic interrelation between the basic production and indicators of technical operation of vehicles and technological transport. Figure 6 shows the theoretical curve of predictive demand for the machinery which properly corresponds to the change of production conditions, which allows optimizing the enterprise's expenditures: with the growth of the production figures - to substantiate the growth of the vehicles' quantity (Figure 6, a, 2016-2018); with the decrease of the figure - to get rid of money losses related to nonproductive idle time of the population of machines (Figure 6, a, 2019).

The model can be useful for engineers responsible for provision of basic production with transport, for entering into an agreement on freight services with contracting agencies. Engineers in the process management of organisations can also use it for planning the working time fund of workshops.

\section{References}

[1] AnyLogic 7 Help Personal Learning Edition 7.2.0 Turbine Service Model (Agent approach).

[2] T. S. Babicheva, S. L. Babichev, Conception of effective number of lanes as basis of traffic optimization, 4th International Conference on Information Technology and Quantitative Management (ITQM) Promoting Business Analytics and Quantitative Management of Technology Местоположение: Asan, South Korea .: AUG 16-18, 2016.

[3] V.I. Bauer, E.S., Kozin, A.V. Bazanov, M.V. Nemkov, A.A. Mukhortov, "The methodic for determining the structure of the park of refuelers for transport divisions in the pipeline industry RJPBBPRJPBCS", Research Journal of Pharmaceutical, Biological and Chemical Sciences, vol. 6(1), 875653.

[4] E. Biondi, C. Boldrini, R. Bruno, Optimal Deployment of Stations for a Car Sharing System with Stochastic Demands: a Queueing Theoretical Perspective, 19th IEEE International Conference on Intelligent Transportation Systems (ITSC) Rio de Janeiro, BRAZIL, NOV 01-04, 2016.

[5] A. Borshchev, The Big Book of Simulation Modeling, Multimethod Modeling with AnyLogic, 6, 2013.

[6] Yanoy Morejon Mesa, Iglesias Coronel, E. Ciro, Use of Queueing Theory to Organization of the Complex Rice Harvest-Transport on the Agroindustrial Rice Complex "Los Palacios", AMA-Agricultural Mechanization In Asia Africa And Latin America, Volume 45, Issue 3, SUM 2014.

[7] Osmanova, M.M. Methodological approaches of calculation of needs and optimal composition of machine-tractor park in agriculture", Economics and Business, 2016, No. 10-2 (75-2).

[8] Jan Ponicky, Juraj Camaj, Martin Kendra. "Possibilities of Simulation Tools for Describing Queuing Theory and Operations Service Lines in Railway Passenger Transport", International Conference on Engineering Science and Management (ESM): Zhengzhou, CHINA: AUG 13-14, 2016.

[9] C. A. Silva, Soares, C. Guedes, J. P. Signoret, "Intermodal terminal cargo handling simulation using Petri nets with predicates", Proceedings of the institution of mechanical engineers part M-journal of engineering for the maritime environment, Volume 229, Issue 4, NOV 2015.

[10] A.V. Ulezko, A.A. Semenov, Ya.I. Denisov, Technological maps as an information basis of planning of needs in agricultural machinery, Agrarian Russia: history and present. Collection of scientific papers. Voronezh: Voronezh State Agrarian University named after. Emperor Peter I, 2010.

[11] E.S. Ventzel, Operations research, Moscow, "Soviet radio", 1972. 